\title{
Overpotential analysis of the Direct Formic Acid Fuel Cell
}

\author{
Takuya Tsujiguchi ${ }^{*}$, Fumihiko Matsuoka, Yu hokari, Yugo Osaka, Akio Kodama \\ ${ }^{1}$ School of Mechanical Engineering, College of Science and Engineering, \\ Kanazawa University, Kakumamachi, Kanazawa, Ishikawa, 920-1192, JAPAN \\ *tsujiguchi@se.kanazawa-u.ac.jp Tel: +81762646473 Fax:+81762646497
}

\begin{abstract}
An overpotential analysis is carried out in the range of $298 \mathrm{~K}-353 \mathrm{~K}$ to clarify the dominant overpotential factor above $333 \mathrm{~K}$ of the direct formic acid fuel cell, DFAFC using $2 \mathrm{mg} \mathrm{cm}^{-2}$ of Pd-black catalyst for the anode. It is found that the mass transport overpotential at the anode which is estimated at a specific current density showing the maximum current density increases from $45 \mathrm{mV}$ to $196 \mathrm{mV}$ when the cell temperature increased from $298 \mathrm{~K}$ to $353 \mathrm{~K}$ although the formic acid crossover flux through the membrane also increases. Moreover, the effect of the loading of microporous layer, MPL, in the range of 1-4 $\mathrm{mg} \mathrm{cm}^{-2}$ at the anode fabricated using Nafion as a binder, which affects the mass transport, on the overpotential behavior is also investigated. It is found that the lower MPL loading is appropriate for the DFAFC operation due to the poor mass transport of the formic acid although the higher MPL loading is appropriate for the hydrogen-oxygen, PEFC, operation. Based on the comparisons of the overpotential distributions between the DFAFC and the PEFC, it is suggested that both the poor mass transport in the anode and the formic acid crossover should be simultaneously improved in order to obtain the higher power density of the DFAFC above $333 \mathrm{~K}$.
\end{abstract}


Keywords: Direct Formic Acid Fuel Cell, Overpotential, Mass transport, Microporous layer

\section{Introduction}

Recently, DFAFCs have attracted much attention due to their higher power density [1] and lower crossover flux [2] compared to those of the direct methanol fuel cells (DMFCs), and they have been considered to be a promising power source for portable devices. Especially, Chang et al. demonstrated that a $550 \mathrm{~mW} \mathrm{~cm}^{-2}$ power density, which is the highest power density for a DFAFC to the best of our knowledge, was obtained using the $\mathrm{Pd}-\mathrm{Ni}_{2} \mathrm{P} / \mathrm{C}$ catalyst for the anode of the DFAFC at $303 \mathrm{~K}$ [3]. This performance is excellent as a direct liquid fuel cell, DLFC, however, it has not reached to the performance of the PEFC.

Generally, PEFCs have been operated at 333-363 K and their power density has exceeded $1 \mathrm{~W} \mathrm{~cm}{ }^{-2}$. Typically, the power density of the fuel cell, such as the PEFC and DMFC, increases with the increasing operating temperature [4,5]. Taking into account this fact, it is expected that the power density of the DFAFC approaches that of the PEFC by increasing the operating temperature. However, it has been reported that the power density of the DFAFC has gradually increased with increasing the operating temperature up to $323 \mathrm{~K}$, but did not increase above $323 \mathrm{~K}[1,6-8]$. As a reason for this phenomenon, it has been reported that the high temperatures lead to an increase water vaporization at the cathode which reduces, e.g., the partial pressure of the oxygen and the mass transport limitation of the anode $[1,8]$. However, these have not been experimentally investigated. Moreover, it has been also reported that the anode kinetic was not improved when the cell temperature increased from $318 \mathrm{~K}$ to $333 \mathrm{~K}$ by the result of the electrochemical impedance spectra, and this is the reason for the cell performance showed plateau when the cell temperature increased from $318 \mathrm{~K}$ to 333K [7]. These findings were derived based on the experimental results, however, the electrochemical impedance spectra was not obtained at the condition showing the maximum 
power output. Therefore, the effect of the cell temperature on the electrode potentials of the anode and the cathode and the overpotential distributions at the various cell temperature should be experimentally investigated at the specific current density showing the maximum power density to specify the factors of power density showing plateau above $323 \mathrm{~K}$.

In this study, an overpotential analysis of the DFAFC was conducted in the range of 298 $353 \mathrm{~K}$ by individually measuring the electrode potentials of the anode and the cathode to experimentally clarify the main factors of the overpotential above $323 \mathrm{~K}$. Since an increase in the operating temperature caused the variation in the mass transport, such as the formic acid crossover [2, 9], the effect of the mass transport on the overpotential distributions of the DFAFC was also investigated using different types of membrane electrode assemblies having various amounts of a microporous layer, MPL, for the anode. They were then compared the PEFC which had the same construction as the DFAFC, but it operated with hydrogen and oxygen to clarify the difference in the overpotential behavior in the high temperature regions above $323 \mathrm{~K}$ between the DFAFC and PEFC.

\section{Experimental}

\subsection{Membrane electrode assembly (MEA) preparation}

NR212 was used as the polymer electrolyte membrane. Palladium black (Alfa Aesar) was used as the catalyst for the anode. The catalyst ink was prepared by dispersing the appropriate amount of the catalyst in a solution of deionized water, isopropyl alcohol, and 5 wt\% Nafion solution (Wako Pure Chemical Industries, Ltd.). For the electrodes preparation, the Pd ink was coated on the microporous layer, MPL, which was prepared with $0.5-4 \mathrm{mg} \mathrm{cm}^{-}$

2 of a carbon black containing 10 wt\% Nafion on the carbon papers (TGP-H-60H, ElectroChem, Inc.). The catalyst loading was $2 \mathrm{mg} \mathrm{cm}^{-2}$, and the ionomer loading of the 
catalyst layer was $10 \mathrm{wt} \%$. For the cathode electrodes, commercial Pt/C (2 mg-Pt cm ${ }^{-2}$, Pt:50 wt\%, GDL; TGP-H-60H, ElectroChem, Inc.) electrodes were purchased from Chemix Co., Ltd. The MEA was then fabricated by sandwiching the membrane between the anode and the cathode and hot pressing them at $408 \mathrm{~K}$ and $5 \mathrm{MPa}$ for $3 \mathrm{~min}$. The projected area of the electrode was $4.84 \mathrm{~cm}^{2}(2.20 \times 2.20 \mathrm{~cm})$.

\subsection{Cell structure}

The cell (FC-05-02H2R, ElectroChem, Inc.) consisted of current collectors, separators, rubber sheets and the MEA. The MEA was sandwiched between the separators made of graphite blocks having serpentine flow channels with a rubber sheet. The formic acid was directly supplied to the graphite flow field without the contact of the metal end plate or tube to avoid the contamination. The Pt wire reference electrode was located in an open compartment independent of the flow field of the anode. It contacted the Pt/C electrode which was the same as the cathode electrode and contacted the NR 212.

\subsection{Measurement of the power generation characteristics}

A formic acid solution was prepared by diluting the formic acid (special grade reagent, Wako Pure Chemical Industries, Ltd.) with purified water which was produced by the distillation using deionized water and corresponded to the A4 grade of JIS K055 (Distilled water, Kyoei Pharmaceutical Co., Ltd.). The current-voltage, i-V, characteristics were measured by linearly sweeping the voltage from the open circuit voltage to zero at the scan rate of $5 \mathrm{mVs}^{-1}$. The $\mathrm{i}-\mathrm{V}$ measurement was conducted at least three times to check the accuracy of the experiment, and it was confirmed that the differences in the cell voltage and the anode/cathode potential among three measurements were less than $5 \mathrm{mV}$. The electrode potentials versus the hydrogen reference electrode were recorded by a data logger (GL 200, 
Graphtech) during the $\mathrm{i}-\mathrm{V}$ measurement. All the electrochemical measurements were conducted using an electrochemical measurement system (Hz-7000, Hokuto Denko, Co., As a cell conditioning, the current-time, i-t, measurement at $0.6 \mathrm{~V}$ with humidified hydrogen/oxygen under $333 \mathrm{~K}$ was conducted for $2 \mathrm{~h}$. In order to check that the cell conditioning was finished or not, three times of i-V measurements were then conducted. The i-t measurement and the $\mathrm{i}-\mathrm{V}$ measurements were repeated until three $\mathrm{i}-\mathrm{V}$ curves were completely fitted.

The cell was operated at temperatures from 298 to 353 K. For the DFAFC operation, 2 $\mathrm{ml} / \mathrm{min}$ of $3 \mathrm{M}$ formic acid was supplied to the anode and $500 \mathrm{ml} / \mathrm{min}$ of oxygen was supplied to the cathode. For the PEFC operation, $500 \mathrm{ml} / \mathrm{min}$ of hydrogen was supplied to the anode, and the $500 \mathrm{ml} / \mathrm{min}$ of oxygen was supplied to the cathode. The stoichiometric ratios of the gases were 15 for hydrogen and 30 for oxygen at $1 \mathrm{~A} \mathrm{~cm}^{-2}$. During the PEFC operation, the hydrogen and oxygen were fully humidified, i.e., they were bubbled through water heated to the cell temperature. During the both operations, $50 \mathrm{ml} / \mathrm{min}$ of fully-humidified hydrogen was also supplied to the reference electrode.

Because the anode performance degraded with the operation due to catalyst poisoning, the following regeneration process (RP) was conducted. After the power generation, the formic acid solution was replaced with fresh water and the cell to wash the anode surface. This washing was continued until the residual cell voltage decreased to $0.1 \mathrm{~V}$ according to the

previous report by Zhou et al. [10]. The anode performance was completely regenerated by this RP process to the initial condition.

\subsection{Measurement and calculation of the crossover flux}

Formic acid crossover flux was estimated by the $\mathrm{CO}_{2}$ gas concentration of the cathode exhaust as following manners $[11,12]$. The DFAFC was operated at the constant voltage of 
$0.4 \mathrm{~V}$. At 1 hour, the cathode exhaust gas through the cold trap was collected in a sampling bag. The $\mathrm{CO}_{2}$ gas concentration in the sampled gas was measured by a microgas chromatograph (GC-400, Agilent). Based on the assumption that the permeated formic acid was completely and immediately oxidized to $\mathrm{CO}_{2}$ by the cathode catalyst, the formic acid crossover flux was estimated from the $\mathrm{CO}_{2}$ concentration in the exhaust gas from the cathode.

\subsection{Overpotential analysis}

It has been widely known that overpotential consists of four losses: (1) activation losses, (2) fuel crossover, (3) ohmic (IR) losses, and (4) mass transport losses. Using these four losses, the cell voltage, $V$, can be estimated as follows [13] ;

$$
\begin{gathered}
V=\left(P_{(c)}-P_{(a)}\right)-\left(i+i_{n}\right) R \\
P_{(c)}=E_{(c)}-A_{(c)} \ln \left(\frac{i+i_{n}}{i_{o(c)}}\right)+B_{(c)} \ln \left(1-\frac{\left(i+i_{n}\right)}{i_{l(c)}}\right) \\
P_{(a)}=E_{(a)}+A_{(a)} \ln \left(\frac{i+i_{n}}{i_{o(a)}}\right)-B_{(a)} \ln \left(1-\frac{\left(i+i_{n}\right)}{i_{l(a)}}\right)
\end{gathered}
$$

In Eqs. (1)-(3), $P$ is the electrode potential, $E$ is the reversible open circuit potential, $i_{\mathrm{n}}$ is the fuel crossover equivalent current density, $R$ is the specific resistance, $A$ is the slope of the Tafel line, $i_{\mathrm{o}}$ is the exchange current density, $B$ is the mass transfer parameter, and $i_{1}$ is the limiting current density. The subscripts (a) and (c) denote the anode and cathode, respectively. On the right-hand side of Eq. (1), the second term is the ohmic loss. On the right-hand side of Eqs. (2)-(3), the second terms are the activation losses, and the last terms are the mass transport losses of the anode and the cathode, respectively. The potentials of the anode and cathode versus the reversible hydrogen electrodes during the i-V measurement, resistance of the cell and the crossover flux were obtained from the experiment, hence, the $A, B$ and $i_{0}$ were estimated as a fitting parameter from Eqs. (2) and (3) by goal seek using an EXCEL spread 
sheet [13]. Based on these results, we obtained five overpotentials, OP, as shown in Table 1. Here, the IR loss was not divided into that of the anode and the cathode since the ohmic resistance between the anode electrode and cathode electrode was measured as the cell resistance. Comparing the cell voltage, the anode/ cathode potentials obtained from experiment and fitting, the differences among them were less than $15 \mathrm{mV}$. Taking into account the fact that the experimental error was less than $5 \mathrm{mV}$, the error of the overpotential was less than $20 \mathrm{mV}$.

\section{Results and discussion}

\subsection{Influence of the operating temperature on the power generation characteristics and the overpotential of the DFAFC}

Figure 1 shows the $\mathrm{i}-\mathrm{V}$ characteristics of the DFAFC under various operating temperatures. These were conducted using the MEA with $1 \mathrm{mg} \mathrm{cm}^{-2}$ of MPL. Below $600 \mathrm{~mA}$ $\mathrm{cm}^{-2}$, the cell voltage increases with the increasing cell temperature suggesting that the activation overpotential is reduced. The maximum current density also increases with the increasing cell temperature up to $333 \mathrm{~K}$, on the other hand, it decreases with the increasing cell temperature above $333 \mathrm{~K}$. Since the reduction of the maximum current density implies a decrease in the mass transport rate, it is suggested that the mass transport rate decreases over $333 \mathrm{~K}$. Figure 2 shows the influence of the operating temperature on the maximum power density obtained from the i-V measurement shown in Fig. 1 and the crossover flux during the i-t measurement. The maximum power density increases with the increasing cell temperature up to $333 \mathrm{~K}$, however, it plateaus even though the operating temperature increased above 333 $\mathrm{K}$ as previous report $[1,6-8]$. Moreover, the crossover flux exponentially increases with the 
increasing cell temperature as reported by Zhu et. al. [8]. This would be due to the swelling effects of the membrane $[1,8,14]$.

The overpotenital distributions at a specific current density showing the maximum power density (298 K; 489 mA cm${ }^{-2}$, $323 \mathrm{~K} ; 692$ mA cm${ }^{-2}$, 353K; 686 mA cm${ }^{-2}$ ) are shown in Fig. 3 (b) and at $500 \mathrm{~mA} \mathrm{~cm}{ }^{-2}$ are shown in Fig. 3 (c). In Fig. 3 (a), the decrease in the anode potential and the increase in the cathode potential with the increasing cell temperature, i.e., the decreases in the overpotential, are observed in the low current density, under $600 \mathrm{~mA} \mathrm{~cm}{ }^{-2}$, regions. Moreover, the decrease in the overpotentials at the anode with the increasing cell temperature is more significant than that at the cathode. This is due to the decrease in the activation loss and this is observed in Fig. 3 (b), (c). In Fig. 3 (b), the activation overpotentials at the anode are $386 \mathrm{mV}$ at $298 \mathrm{~K}, 300 \mathrm{mV}$ at $323 \mathrm{~K}$ and $146 \mathrm{mV}$ at $353 \mathrm{~K}$. Based on these results, it is suggested that the increase in the cell voltage with the increasing cell temperature shown in Fig. 1 below $600 \mathrm{~mA} \mathrm{~cm}^{-2}$ is mainly caused by the decrease in the activation loss at the anode. On the other hand, the anode potential of $353 \mathrm{~K}$ shows a significant increase at the high current density compared that of $323 \mathrm{~K}$ in Fig. 3 (a). This is due to increase in the mass transport overpotential at the anode with the increasing cell temperature as shown in Fig. 3 (c). The mass transport overpotentials at the anode indicated in Fig. 3 (b) are 45 mV at $298 \mathrm{~K}$, $86 \mathrm{~K}$ at $323 \mathrm{~K}$ and $196 \mathrm{mV}$ at $353 \mathrm{~K}$ and indicated in Fig. 3 (c) are $47 \mathrm{mV}$ at $298 \mathrm{~K}, 58 \mathrm{mV}$ at $323 \mathrm{~K}$ and $104 \mathrm{mV}$ at $353 \mathrm{~K}$. It is found that the mass transport overpotentials at the anode significantly increases with the increasing cell temperature irrespective of the current density, and this is more significant in the case of Fig. 3 (b). Referring to the overpotential at the cathode, the activation and mass transport overpotentials did not vary or slightly decreased with the increasing cell temperature although the crossover flux was significantly increased with the increasing cell temperature as shown in Fig. 2. This is because the increase in the overpotential due to the mixed potential by the crossover effect and /or the reduction in the 
partial pressure of the oxygen by the increase in the water vaporization is compensated by the decrease in the activation loss with the increasing cell temperature. Based on these results, the reason why the maximum power density shows a plateau over $333 \mathrm{~K}$ is considered to be mainly caused by the increase in the mass transport overpotential at the anode.

Regarding on the formic acid transport in the catalyst layer and the crossover flux, Bausker and Rice demonstrated that the performance could be enhanced by forming pores in the anode catalyst layer due to the improvement of the mass transport by the pores, however, the formic acid crossover did not increase [15]. These results imply that the formic acid flux in the anode catalyst layer and it from the anode to the cathode through the electrolyte membrane has to be individually considered. The formic acid crossover is caused by not only the concentration difference between the anode and cathode, but also the swelling effect of the membrane as previously explained $[1,8,14]$. In their study, the formic acid transport in the anode catalyst layer would be promoted by forming the pores, on the other hand, the swelling effect of the membrane would not be changed. Therefore, the crossover flux did not change due to the slight increase in the concentration of the formic acid by the pores formed in the anode catalyst layer. On the contrary, in this study, the swelling effect of the electrolyte (membrane and the Nafion in the anode catalyst layer) would increase and the crossover flux increases with the increasing cell temperature. Moreover, the increased formic acid in the electrolyte would not contribute to the electrode reaction. In other words, the high temperature would lead to an increase in the formic acid transport only in the electrolyte and would not lead to an increase in the anode catalyst layer which contributes to the electrode reaction. Based on these reasons, the mass transport overpotential at the anode did not decrease although the formic acid crossover increased with the increasing cell temperature in this study. The factors for the increase in the mass transport overpotential at the anode with the increasing cell temperature would be caused by the increase in the volume of the $\mathrm{CO}_{2}$, the decrease in capillary force due 
to the increase in the surface tension and the increase in the gas phase in the anode catalyst layer due to the increase in vapor pressure, etc. These would be closely interrelated with each other. Therefore, a further study of the mass transport in the anode catalyst layer is needed and this will be reported elsewhere.

\subsection{Influence of MPL loading on the power generation characteristics and the overpotential .}

\subsubsection{Effect of the MPL loading on the maximum power density}

For the high temperature operation of the DFAFC, the mass transport overpotential at the anode is significant, therefore, the effect of the MPL loading of the anode electrode on the maximum power density was investigated, and the results are shown in Fig. 4. For comparison, the maximum power densities with the PEFC are also shown in Fig. 4. Moreover, the average cell resistances during the $\mathrm{i}-\mathrm{V}$ measurement are shown in Table 2. For the DFAFC, the maximum power density slightly increases with the decreasing MPL loading and gradually increases or plateaus with the increasing cell temperature. On the other hand, the maximum power density of the PEFC significantly increased with the increasing MPL loading, and the degree of change is more significant in the high temperature region. The difference in the effect of the anode MPL loading on the maximum power density between the DFAFC and PEFC is caused by the difference in the mass transport.

For the low MPL loading ( 0.6 and $1.9 \mathrm{mg} \mathrm{cm}^{-2}$ ), the maximum power density of the PEFC does not increase with the increasing cell temperature. These behaviors of the PEFC would be related to the moisture content of the electrolyte membrane. As shown in Table 2, the cell resistance increases with the increasing cell temperature for the low MPL loading, on the other hand, the cell resistance does not increase with the increasing cell temperature for the high MPL loading. Based on these results, it is considered that the anode MPL contributes to 
maintaining the water content in the membrane. Regarding the effect of the anode MPL of the PEFC on the water transport, there are two proposals. Some researchers reported that the anode MPL did not contribute to the power generation characteristics of the PEFC [16-18], on the other hand, Blanco et al. reported that water accumulation in the anode catalyst layer could be inhibited and water removal from the cathode could be also promoted by the anode MPL layer [19]. They considered that the reason why the positive effect by the anode MPL was obtained in their study was due to the high air flow ratio. In our study, the anode and the cathode gas flow rates are also as high as in their study, therefore, the anode MPL has a positive effect on the performance of the PEFC. Taking into account their results and the fact that the cell resistance is low at a high MPL loading and high temperature in our study, water accumulated in the anode and the cathode catalyst layer would be transported to the membrane resulting in the increased moisture content of the membrane and the mass transport rate in the anode and cathode catalyst layer by the anode MPL, hence, the performance of the PEFC increases with the increasing MPL loading. On the contrary, the water content of the electrolyte membrane is high since liquid fuel is supplied to the anode in the DFAFC. Additionally, the increase in the MPL loading causes a decrease in the mass transport rate since the diffusion rate of the formic acid is much lower than that of the hydrogen. From these reasons, the power density of the DFAFC decreases with the increasing MPL loading although that of the PEFC increases with the increasing MPL loading.

Figure 5 shows the effect of the MPL loading and the operating temperature on the formic acid crossover flux. In the low temperature regions, below $333 \mathrm{~K}$, there are no significant differences in the crossover flux irrespective of the MPL loading, on the other hand, in the high temperature regions, above $333 \mathrm{~K}$, a significant difference in the crossover flux appears. In the high temperature regions, the crossover fluxes of 0.6 and $1 \mathrm{mg} \mathrm{cm} \mathrm{cm}^{-2}$ significantly increase with the increasing temperature, and it increases with the increasing 
MPL loading although the crossover flux of 0.6 and $1.0 \mathrm{mg} \mathrm{cm}^{-2}$ are almost the same. The increase in the crossover flux with the decreasing anode MPL loading would imply an increase in the mass transport rate at the anode catalyst layer, unlike the case of Fig. 2, since the swelling effect of the membrane is not dependent on the MPL loading, but on the cell temperature. Based on these results, it is suggested that the increase in the MPL loading caused the decrease in the mass transport rate of the formic acid. Moreover, it was also found that the increase in the mass transport ratio in the anode catalyst layer influenced the power density more than the increase in the crossover flux by decreasing the MPL loading since a high power density is obtained at the low MPL loading.

\subsubsection{Effect of the MPL loading on the electrode potentials}

The electrode potentials during the $\mathrm{i}-\mathrm{V}$ measurements using the MEAs having different MPL loadings are shown in Fig. 6 (a). The overpotential distributions at the specific current density showing the maximum power density $\left(0.6 \mathrm{mg} \mathrm{cm}^{-2} ; 784 \mathrm{~mA} \mathrm{~cm}{ }^{-2}, 1.0 \mathrm{mg} \mathrm{cm}{ }^{-2} ; 701\right.$ $\mathrm{mA} \mathrm{cm}{ }^{-2}, 1.9 \mathrm{mg} \mathrm{cm}^{-2}, 3.9 \mathrm{mg} \mathrm{cm}^{-2} 370 \mathrm{~mA} \mathrm{~cm}^{-2}$ ) and at $500 \mathrm{~mA} \mathrm{~cm}{ }^{-2}$ using the MEAs having different MPL loadings are shown in Fig. 6 (b) and Fig. 6 (c), respectively. The cell temperature is fixed at 333 K. From Fig. 6 (a), it is found that the maximum current density decreases with the increasing MPL loading. Especially, the anode potential drastically increases at a low current density for the $3.9 \mathrm{mg} \mathrm{cm}^{-2}$ MPL loading. Moreover, the difference in the cathode potential is also observed although a similar cathode electrode is used for all the MEAs.

There is no clear trend in the overpotential distribution since the current density showing the maximum power density is different in each MEA in Fig. 6 (b). However, in Fig. 6 (c), which compared the overpotential at the same current density, i.e., $500 \mathrm{~mA} \mathrm{~cm}{ }^{-2}$, it is found

that the mass transport overpotential at the anode is high at the $3.9 \mathrm{mg} \mathrm{cm}^{-2} \mathrm{MPL}$ loading and 
the mass transport overpotential at the cathode increases with the increasing anode MPL loading. The high anode mass transport overpotential at $3.9 \mathrm{mg} \mathrm{cm}^{-2}$ due to the increase in the mass transport resistance by increasing the MPL, on the other hand, the increase in the mass transport overpotential at the cathode with the increasing anode MPL loading is an interesting behavior. As a reason for the cathode overpotential behavior, it is considered that flooding, which is a liquid water accumulation, at the cathode becomes more serious with the increasing MPL loading. The water transport through the membrane in the fuel cell using a polymer electrolyte contained in the DFAFC is considered to be governed by three transport mechanisms; electro-osmotic drag, diffusion and convection as follows:

$$
J_{w}=J_{w e o}+J_{w d i f f}+J_{w c}
$$

where $J_{\text {weo }}$ represents the water flux by electro-osmotic drag, $J_{\text {wdiff }}$ represents the water flux by diffusion and $J_{\mathrm{wc}}$ represents the water flux by convection. Note that the positive flux means the flux from the anode to the cathode and the negative flux means the flux from the cathode to the anode [20]. In our previous study, it was found that the sum of the $J_{\text {wdiff }}$ and $J_{\mathrm{wc}}$, was a negative value, i.e., the direction of water transport due to the sum of the diffusion and the convection was from the cathode to the anode, although $J_{\mathrm{w}}$ in the DFAFC showed a positive value, i.e., water was totally transported from the anode to the cathode when the current density was above $150 \mathrm{~mA} \mathrm{~cm}^{-2}$. Moreover, it was also found that the $J_{\mathrm{w}}$ from the anode to the cathode increased with the increasing membrane thickness since the absolute value of the $J_{\text {wdiff }}+J_{\text {wc }}$, which was a negative value, decreased [20]. The absolute value of $J_{\text {wdiff }}+J_{\text {wc }}$ is also considered to decrease by the increasing MPL loading resulting in the increase of $J_{\mathrm{w}}$ from the anode to the cathode. Due to this, water easily accumulates at the cathode, i.e., the flooding becomes more serious, hence, the mass transport overpotential at the cathode increases with the increasing anode MPL loading. This water transport behavior would be caused by using formic acid as a fuel, which is a liquid and shows a hygroscopic property [8, 
21], and it is different from the PEFC using gas as a fuel. Based on these results, it was found that the low anode MPL loading is appropriate for the DFAFC since the high anode MPL loading caused not only an increase in the anode overpotential, but also an increase in the cathode overpotential during the DFAFC operation.

\subsection{Comparison of the overpotential between DFAFC and PEFC}

In Fig. 4, there was a significant difference in the maximum power density between the PEFC obtained at $3.9 \mathrm{mg} \mathrm{cm}^{-2}$ and $343 \mathrm{~K}, 850 \mathrm{~mW} \mathrm{~cm}^{-2}$, and the DFAFC obtained at $0.6 \mathrm{mg}$

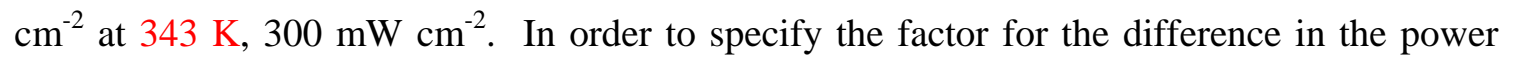
density between the DFAFC and PEFC, the electrode potentials during the $\mathrm{i}-\mathrm{V}$ measurement and the overpotential distributions at the specific current density (DFAFC; $716 \mathrm{~mA} \mathrm{~cm}{ }^{-2}$, PEFC; $1527 \mathrm{~mA} \mathrm{~cm}^{-2}$ ) showing the maximum power density and at $500 \mathrm{~mA} \mathrm{~cm}{ }^{-2}$ is compared between the PEFC and DFAFC. The results are shown in Fig. 7. Here the MPL loadings are $0.6 \mathrm{mg} \mathrm{cm}^{-2}$ in the DFAFC and $3.9 \mathrm{mg} \mathrm{cm}^{-2}$ in the PEFC and the cell temperatures are $343 \mathrm{~K}$. From Fig. 7 (a), it is found that the difference in the cathode open circuit potential is about $170 \mathrm{mV}$ although the anode potential is almost similar, i.e., PEFC $9 \mathrm{mV}$ and DFAFC $-5 \mathrm{mV}$. This is due to the mixed potential by the formic acid crossover. The anode potential of the DFAFC linearly increases with the increasing current density, on the other hand, that of the PEFC slightly increases with the increasing current density. The cathode potential of the DFAFC linearly decreases with the increasing current density irrespective of the current density, on the other hand, the cathode potential of the PEFC decreases with the current density having a similar slope to the DFAFC below $600 \mathrm{~mA} \mathrm{~cm}^{-2}$, then it gradually decreases in the range of the current density of $600-1400 \mathrm{~mA} \mathrm{~cm}^{-2}$, finally, it suddenly decreases above $1400 \mathrm{~mA} \mathrm{~cm}{ }^{-2}$. The difference in the slope of the cathode potential between the DFAFC and the PEFC in the middle current density range $\left(600-1400 \mathrm{~mA} \mathrm{~cm}^{-2}\right)$ is caused by the difference 
in the ohmic resistance, and the sudden drop in the cathode potential of the PEFC is caused by flooding of the cathode due to the fully humidified operation.

Focusing on the overpotential distributions at the current density showing the maximum power density, Fig. 7 (b), the cathode overpotential (sum of the cathode act and the cathode mass) of the DFAFC is almost similar to that of the PEFC although the ratio is different. Therefore, it was found that there is a significant difference in the anode overpotential between the DFAFC and the PEFC when comparing at the maximum power density. Moreover, from Fig. 7 (c), which compares the overpotential distributions at the same current density, the activation overpotential at the cathode of the DFAFC is also higher than that of the PEFC. This difference is about $150 \mathrm{mV}$ and it is considered to be caused by the formic acid crossover. It has been widely known that the activation overpotential at the anode and the cathode overpotential due to the crossover are serious challenges among the DLFC. For the DFAFC, it is confirmed that the activation overpotential at the anode and the cathode overpotential due to the crossover is also significant when comparing them with the PEFC although it was reported that the formic acid crossover was relatively lower [2], and the Pd based DFAFC showed a high power density in the DLFC [8]. Moreover, the mass transport overpotential at the anode is also high since it corresponded to half of the anode overpotential in the DFAFC. Based on these results, i.e., conflicting results, that an increase in the mass transport rate is required from the view point of the reduction in the mass transport overpotential at the anode, on the other hand, the decrease in the formic acid crossover, which means a decrease in the mass transport rate, are obtained. In order to solve these conflicting problems, the reduction of the mass transport resistance of the anode electrode by increasing the porosity of the anode catalyst layer, and the development of a cathode catalyst which has no reactivity with formic acid are expected. 


\section{Conclusions}

The overpotential analysis of the DFAFC was carried out to determine the reason why the power density of the DFAFC did not increase with the increasing cell temperature above $333 \mathrm{~K}$. It was found that the activation overpotential at the anode decreased with the increasing cell temperature, however, the mass transport overpotential at the anode increased with the increasing cell temperature although the formic acid crossover flux increased. The effect of the anode MPL loading on the power generation characteristics was also investigated by comparing that of the PEFC. It was found that the power density of the DFAFC increased with the decreasing MPL loading although that of PEFC increased with the increasing anode MPL loading. Considering the fact that the formic acid crossover flux increased and the mass transport overpotential at the anode decreased with the decreasing anode MPL loading, it was found that the anode mass transport resistance could be reduced by decreasing the anode MPL loading. Moreover, the mass transport overpotential at the cathode increased with the increasing anode MPL loading.

From the comparisons of the overpotential distributions between the DFAFC and the PEFC, both the activation and the mass transport overpotentials at the anode were significant. Moreover, the activation overpotential at the cathode by the formic acid crossover was also significant. Therefore, it was suggested that both the poor mass transport in the anode and the formic acid crossover should be simultaneously improved in order to obtain a higher power density above $333 \mathrm{~K}$ for the DFAFC.

\section{Acknowledgement}


A part of this study was supported by the Hokuriku Industrial Advancement Center, and the JST PREST.

\section{References}

[1] S. Ha, R. Larsen, Y. Zhu, R.I. Masel, Fuel Cells 4 (2004) 337-343.

[2] K.-J. Jeong, C.M. Miesse, J.-H. Choi, J. Lee, J. Han, S.P. Yoon, S.W. Nam, T.-H. Lim, T.G. Lee, J. Power Sources 168 (2007) 119-125.

[3] J. Chang, L. Feng, C. Liu, W. Xing, X. Hu, Angew. Chem. Int. Ed. Engl. 53 (2014) 122-126.

[4] C. Song, Y. Tang, J.L. Zhang, J. Zhang, H. Wang, J. Shen, S. McDermid, J. Li, P. Kozak, Electrochim. Acta 52 (2007) 2552-2561.

[5] V. Gogel, T. Frey, Z. Yongsheng, K.. Friedrich, L. Jörissen, J. Garche, J. Power Sources 127 (2004) 172.

[6] Y. Zhu, Z. Khan, R. Masel, J. Power Sources 139 (2005) 15-20.

[7] W.S. Jung, J. Han, S. Ha, J. Power Sources 173 (2007) 53-59.

[8] Y. Zhu, S. Ha, R.I. Masel, J. Power Sources, 130 (1-2) (2004) 8-14.

[9] X. Wang, J.-M. Hu, I.-M. Hsing, J. Electroanal. Chem. 562 (2004) 73-80.

[10] Y. Zhou, J. Liu, J. Ye, Z. Zou, J. Gu, T. Yu, A. Yang, Electrochim. Acta 55 (2010) 5024.

[11] N. Nakagawa, T. Tsujiguchi, S. Sakurai, R. Aoki, Performance of an active direct methanol fuel cell fed with neat methanol, J. Power Sources. 219 (2012) 325-332. doi:10.1016/j.jpowsour.2012.07.062.

[12] V. Gogel, T. Frey, Z. Yongsheng, K.. Friedrich, L. Jörissen, J. Garche, Performance and methanol permeation of direct methanol fuel cells: dependence on operating 
conditions and on electrode structure, J. Power Sources. 127 (2004) 172-180. doi:10.1016/j.jpowsour.2003.09.035.

[13] S. Ha, Z. Dunbar, R. Masel, J. Power Sources 158 (2006) 129.

[14] X. Ren, W. Henderson, S. Gottesfeld, J. Electrochem. Soc., 144 (1997), p. 267

[15] A.S. Bauska r, C. Rice, El ect r ochim. Act a 62 (2012) 36.

[16] T. Kim, S. Lee, H. Park, Int. J. Hydrogen Energy, 35 (2010) 8631-8643.

[17] J.P. Owejan, J.E. Owejan, W. Gu, T.A. Trabold, T.W. Tighe, M.F. Mathias, J. Electrochem. Soc., 157 (2010) B1456-B1464.

[18] T. Kitahara, T. Konomi, H. Nakajima, Y. Tateishi, M. Murata, N. Haak, P.Wilde, ECS Trans, 16 (2008), 1603-1613

[19] M. Blanco, D.P. Wilkinson, Int. J. Hydrogen Energy, 39 (2014) 16390

[20] T. Tsujiguchi, T. Iwakami, S. Hirano, N. Nakagawa, J. Power Sources 250 (2014) 266.

[21] S. Uhm, S. Chung, J. Lee, Journal of Power Sources 178 (2008) 34-43

\section{Figure captions}

Figure 1 Effect of the operating temperature on the i-V characteristics of the DFAFC (MPL loading: $1 \mathrm{mg} \mathrm{cm}^{-2}$ ).

Figure 2 Effect of the operating temperature on the maximum power density and the crossover flux of the DFAFC (MPL loading: $1 \mathrm{mg} \mathrm{cm}^{-2}$ ).

Figure 3 Effect of the operating temperature on the electrode potentials and the overpotential distributions (MPL loading: $1 \mathrm{mg} \mathrm{cm}^{-2}$ ).

Figure 4 Effect of the operating temperature and the MPL loading on the maximum power density operated with DFAFC and PEFC.

Figure 5 Effect of the MPL loading and operating temperature on the crossover flux (DFAFC operation). 
Figure 6 Effect of MPL loading on the electrode potentials and overpotential distributions (Cell temperature: $333 \mathrm{~K}$ ).

Figure 7 Comparison of the electrode potentials and overpotential distributions between DFAFC and PEFC at cell temperature of $343 \mathrm{~K}$ (MPL loading; $0.6 \mathrm{mg} \mathrm{cm}^{-2}$ at DFAFC, $3.9 \mathrm{mg} \mathrm{cm}^{-2}$ at PEFC). 


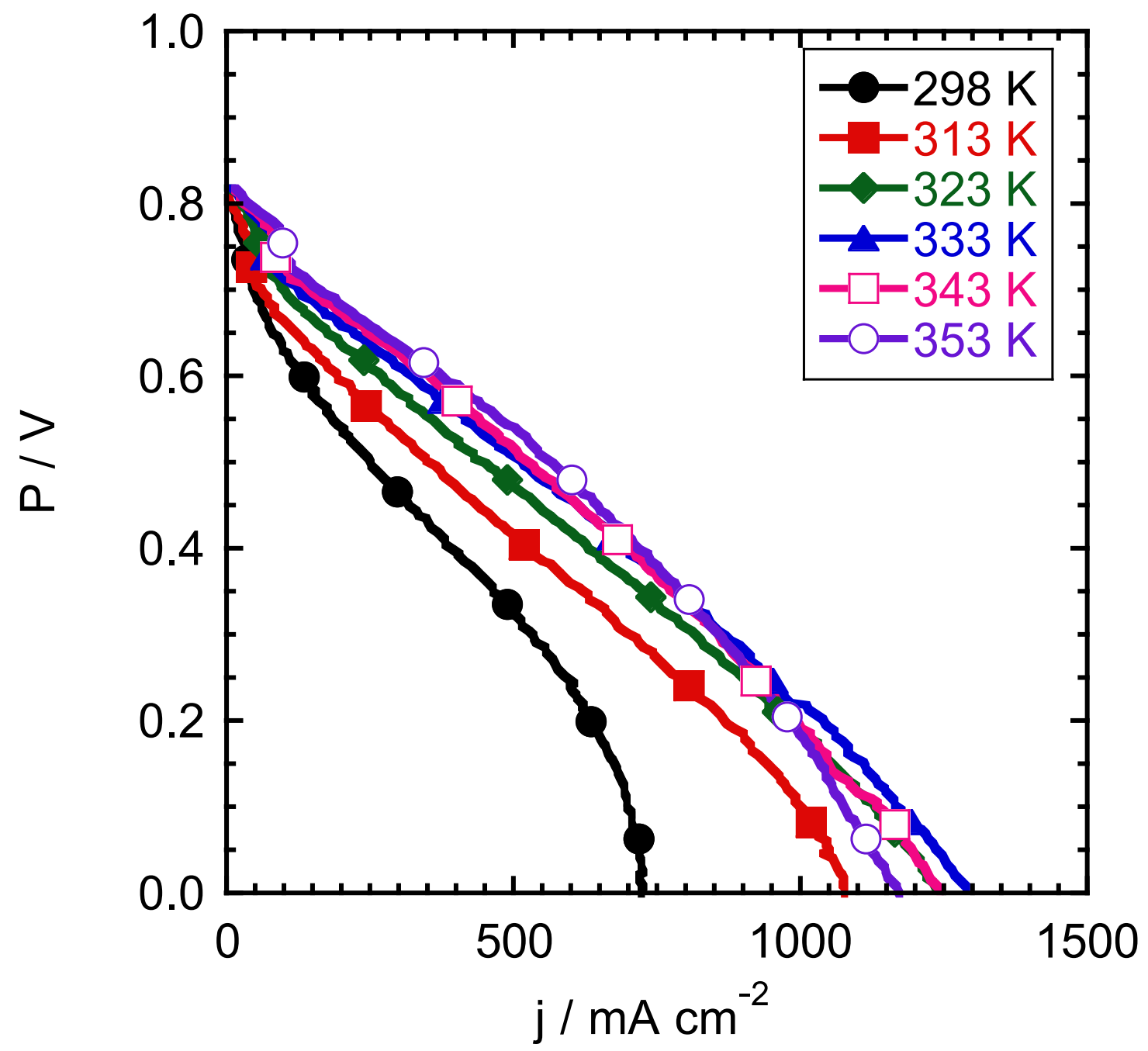

Figure 1 Effect of the operating temperature on the $\mathrm{i}-\mathrm{V}$ characteristics of the DFAFC. (MPL loading: $1 \mathrm{mg} \mathrm{cm}^{-2}$ ) 


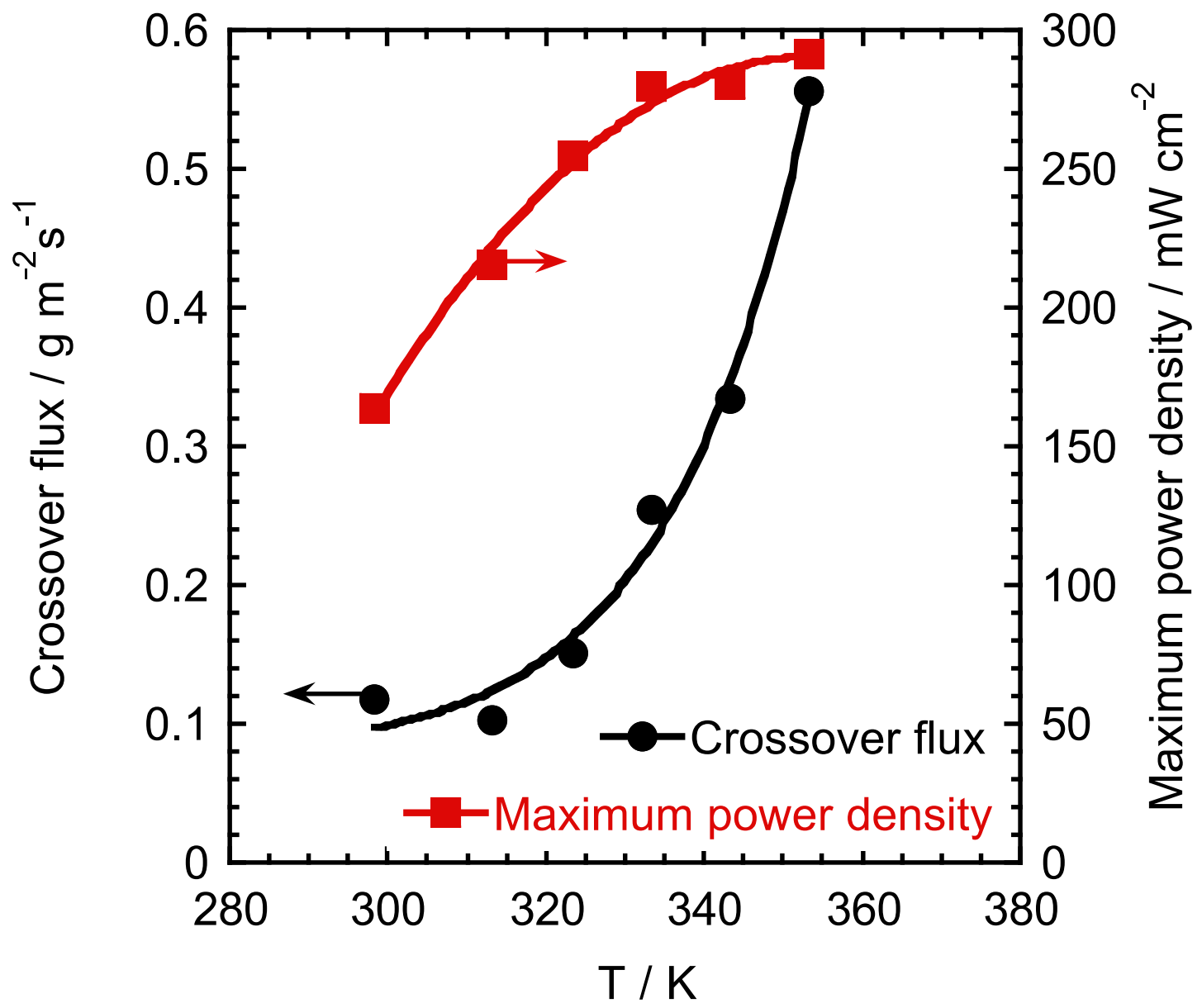

Figure 2 Effect of the operating temperature on the maximum power density and the crossover flux of the DFAFC. (MPL loading: $1 \mathrm{mg} \mathrm{cm}^{-2}$ ) 


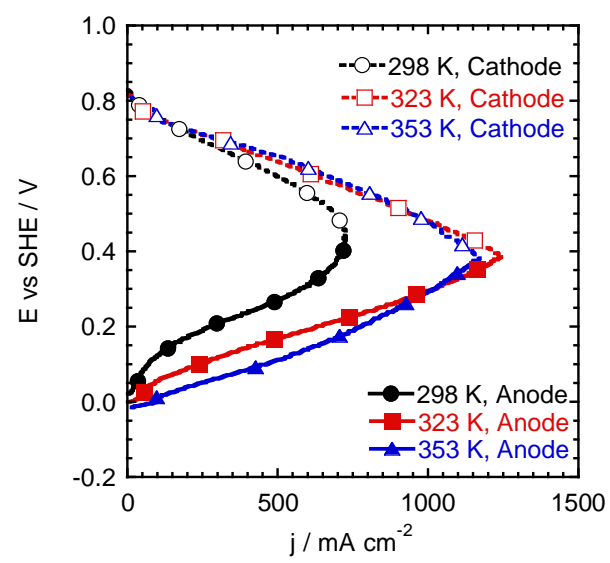

(a) Electrode potentials

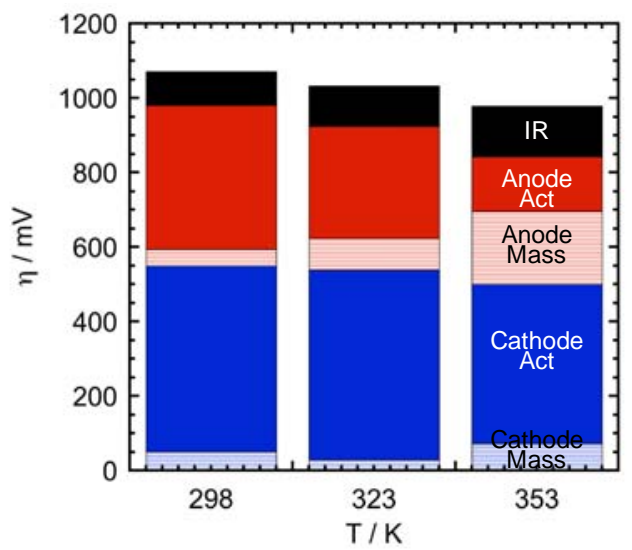

(b) Overpotential distributions at the specific current density showing the maximum power density (298 K: 489 mA cm${ }^{-2}$, $323 \mathrm{~K}: 692 \mathrm{~mA} \mathrm{~cm}^{-2}$, 353K: $686 \mathrm{~mA} \mathrm{~cm}^{-2}$ ).

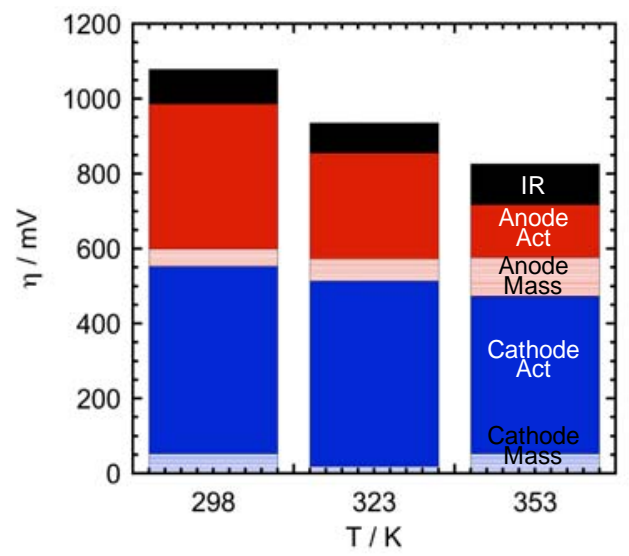

(c) Overpotential distributions at $500 \mathrm{~mA} \mathrm{~cm}^{-2}$.

Figure 3 Effect of the operating temperature on the electrode potentials and the overpotential distributions (MPL loading: $1 \mathrm{mg} \mathrm{cm}^{-2}$ ) 


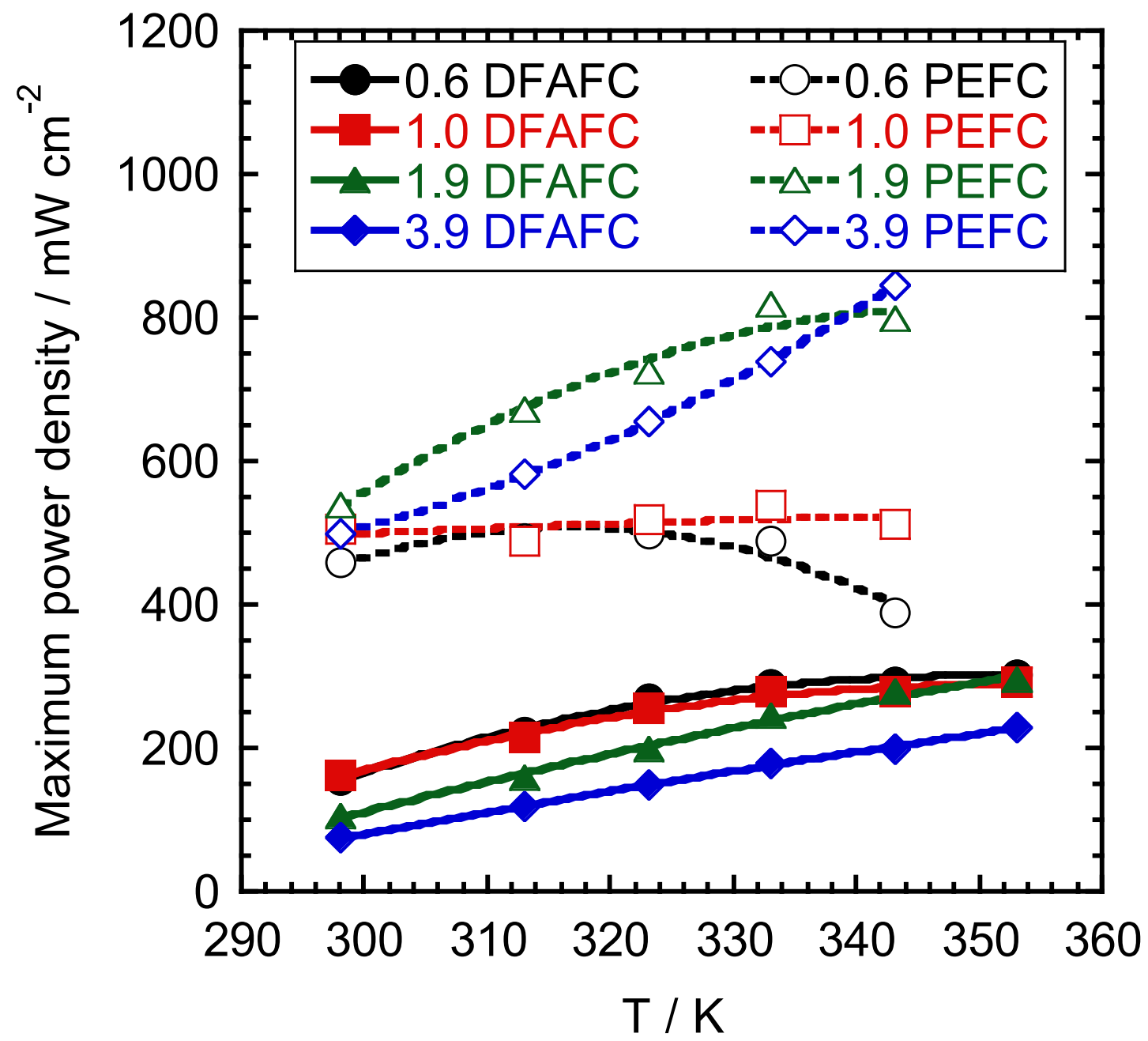

Figure 4 Effect of the operating temperature and the MPL loading on the maximum power density operated with DFAFC and PEFC 


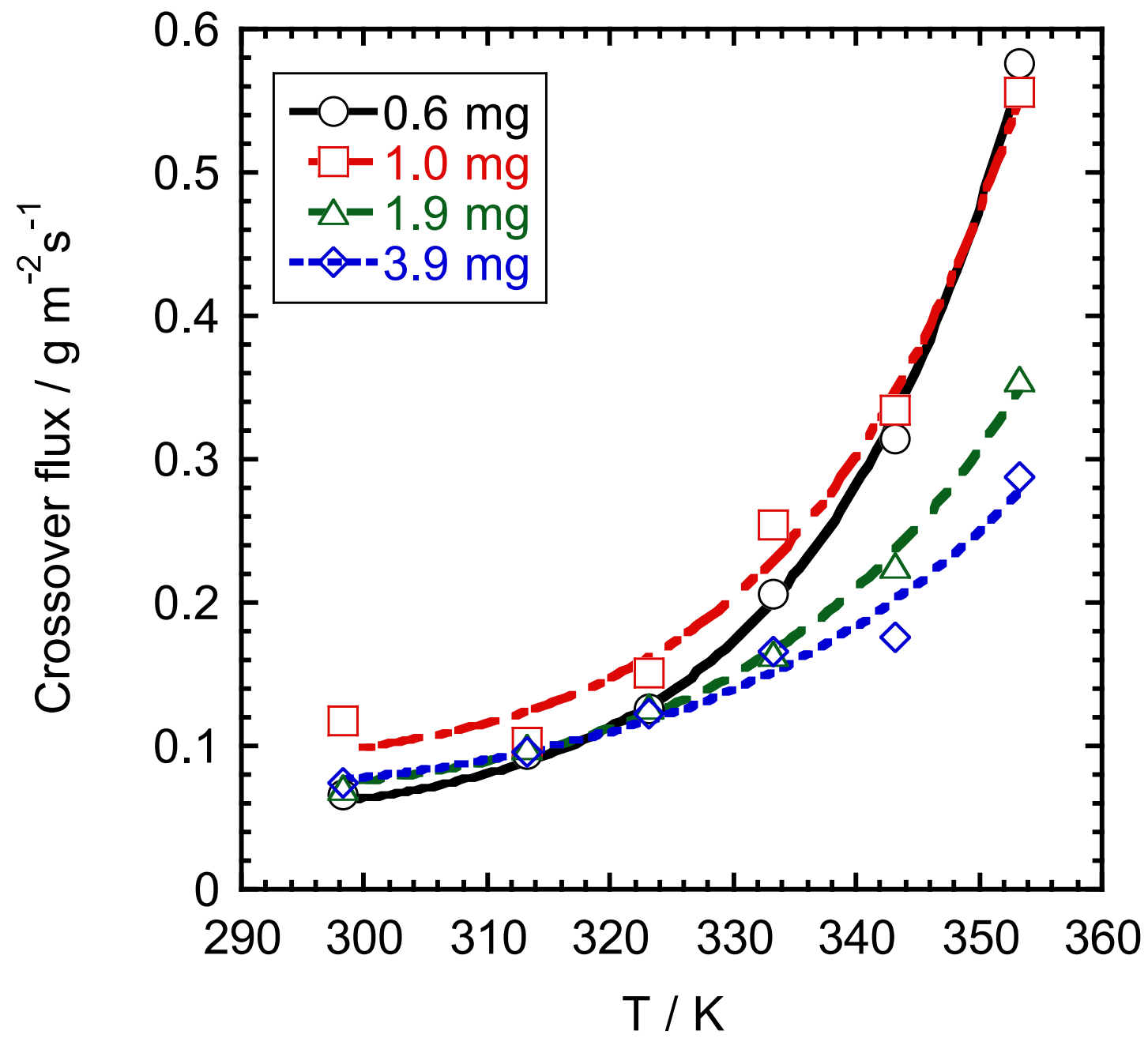

Figure 5 Effect of the MPL loading and operating temperature on the crossover flux (DFAFC operation) 


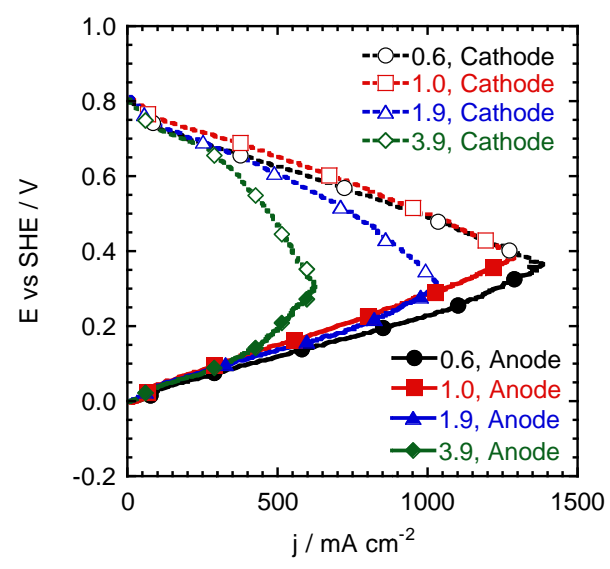

(a) Electrode potentials

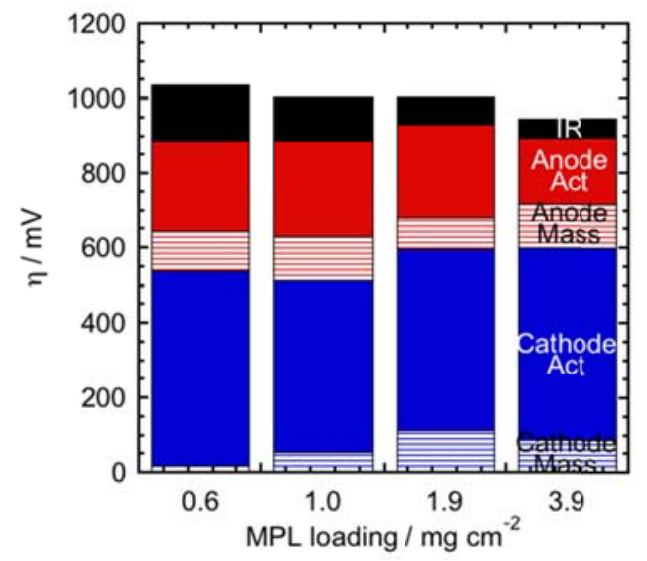

(b) Overpotential distributions at the specific current density showing the maximum power density

(0.6: $784 \mathrm{~mA} \mathrm{~cm}^{-2}$, 1.0: $701 \mathrm{~mA} \mathrm{~cm}{ }^{-2}$, 1.9: $613 \mathrm{~mA} \mathrm{~cm}^{-2}, 3.9: 370 \mathrm{~mA} \mathrm{~cm}{ }^{-2}$ )

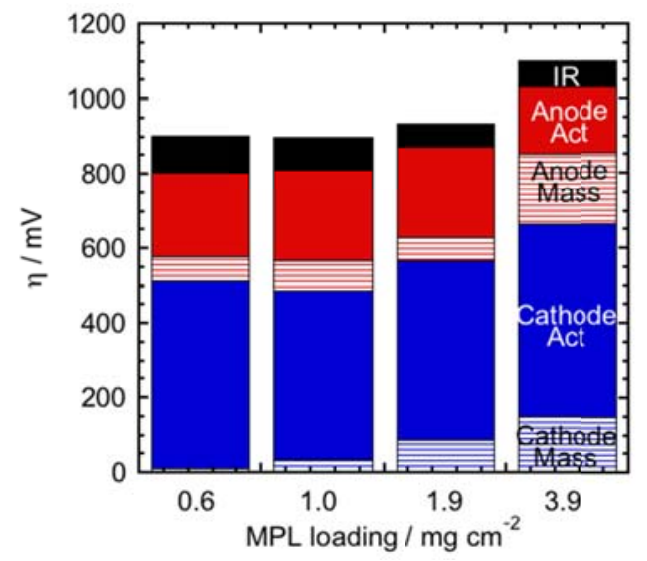

(c) Overpotential distributions at $500 \mathrm{~mA} \mathrm{~cm}^{-2}$

Figure 6 Effect of MPL loading on the electrode potentials and overpotential distributions (Cell temperature: $333 \mathrm{~K}$ ) 


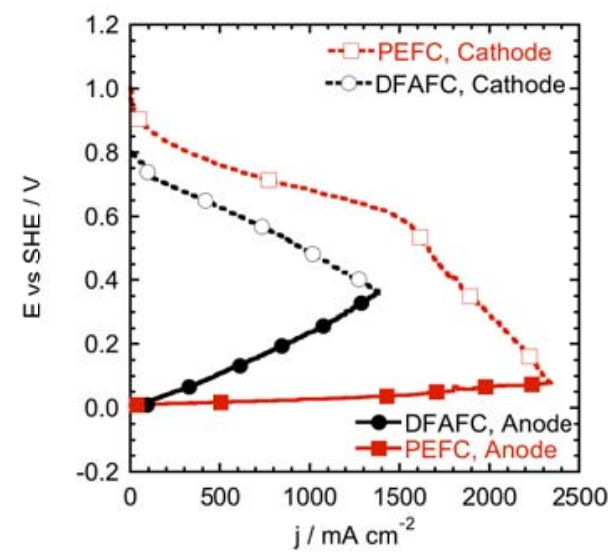

(a) Electrode potentials

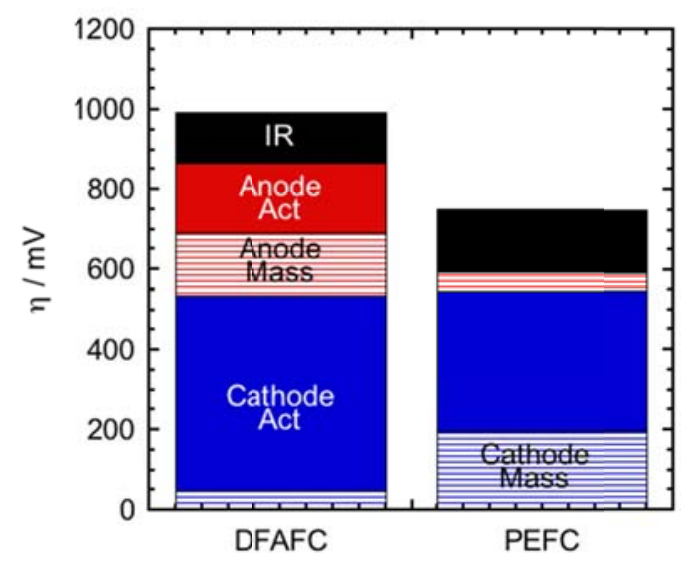

(b) Overpotential distributions at the specific current density showing the maximum power density (DFAFC: $716 \mathrm{~mA} \mathrm{~cm}^{-2}$, PEFC $1527 \mathrm{~mA} \mathrm{~cm}^{-2}$ )

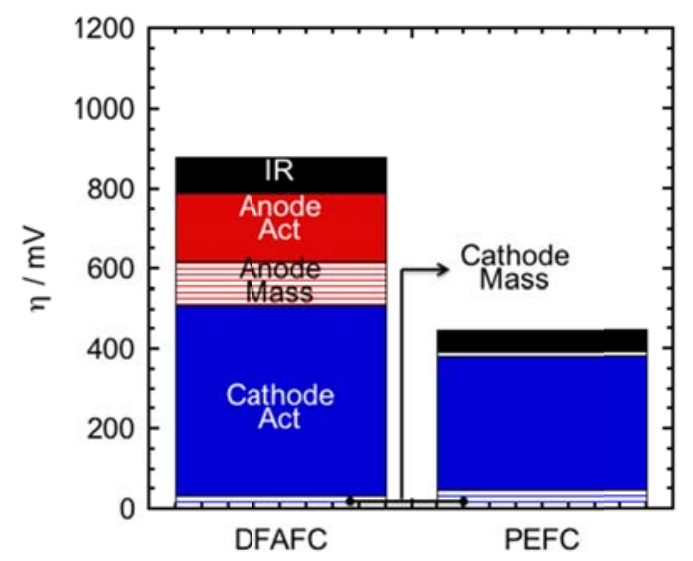

(c) Overpotential distributions at $500 \mathrm{~mA} \mathrm{~cm}^{-2}$

Figure 7 Comparison of the electrode potentials and overpotential distributions between DFAFC and PEFC at cell temperature of $343 \mathrm{~K}$ (MPL loading; $0.6 \mathrm{mg} \mathrm{cm}^{-2}$ at DFAFC, $3.9 \mathrm{mg} \mathrm{cm}^{-2}$ at PEFC) 


\section{Table 1 Overpotentials}

$$
\begin{aligned}
& \text { Anode } \\
& \text { Cathode } \\
& \text { Activation } \quad O P_{(a) a c t}=A_{(a)} \ln \left(\frac{i+i_{n}}{i_{o(a)}}\right) \quad O P_{(c) a c t}=A_{(c)} \ln \left(\frac{i+i_{n}}{i_{o(c)}}\right) \\
& \text { Mass transport } \quad O P_{(a) m a s s}=B_{(a)} \ln \left(1-\frac{\left(i+i_{n}\right)}{i_{l(a)}}\right) \quad O P_{(c) m a s s}=B_{(c)} \ln \left(1-\frac{\left(i+i_{n}\right)}{i_{l(c)}}\right)
\end{aligned}
$$

IR

$$
\left(i+i_{n}\right) R
$$


Table 2 Average cell resistance during the i-V measurements.

\begin{tabular}{cccccccc}
\hline $\begin{array}{c}\text { MPL loading } \\
{\left[\mathrm{mg} / \mathrm{cm}^{2}\right]}\end{array}$ & Operation & 298 & 313 & 323 & 333 & 343 & 353 \\
\hline \multirow{2}{*}{0.6} & DFAFC & 30.4 & 29.2 & 30.1 & 29.9 & 30.7 & 33.2 \\
& PEFC & 37.6 & 37.5 & 37.2 & 39.5 & 58.7 & \\
\multirow{2}{*}{1.0} & DFAFC & 31.5 & 29.5 & 29.3 & 26.6 & 26.3 & 29.1 \\
& PEFC & 38.4 & 32.9 & 34.0 & 35.0 & 37.0 & \\
\multirow{2}{*}{1.9} & DFAFC & 27.6 & 24.9 & 24.5 & 22.2 & 20.9 & 19.8 \\
& PEFC & 28.8 & 27.0 & 26.8 & 27.2 & 23.2 & \\
\multirow{2}{*}{3.9} & DFAFC & 26.3 & 22.9 & 21.8 & 25.2 & 22.5 & 16.5 \\
& PEFC & 28.5 & 24.9 & 24.1 & 22.4 & 21.2 & \\
\hline
\end{tabular}

